\title{
Married adolescents: A review of programmes
}

\author{
Auralice Graft \\ Nicole Haberland \\ Population Council \\ Rachel E. Goldberg
}

Follow this and additional works at: https://knowledgecommons.popcouncil.org/departments_sbsr-pgy

Part of the Family, Life Course, and Society Commons, Gender and Sexuality Commons, and the International Public Health Commons

How does access to this work benefit you? Let us know!

\section{Recommended Citation}

Graft, Auralice, Nicole Haberland, and Rachel E. Goldberg. 2004. "Married adolescents: A review of programmes," paper prepared for the WHO/UNFPA/Population Council Technical Consultation on Married Adolescents. New York: Population Council. 


\title{
Married Adolescents: A Review of Programmes
}

\author{
Auralice Graft \\ Nicole Haberland \\ Rachel Goldberg
}

Paper prepared for the WHO/UNFPA/Population Council

Technical Consultation on Married Adolescents

WHO, Geneva

9-12 December 2003 


\section{INTRODUCTION}

Historically, major adolescent and reproductive health initiatives have failed to explicitly consider the needs of married adolescents. Adolescent programmes, many in the form of schoolbased projects, youth centres, youth-friendly clinics, and peer education programmes, have for the most part focused their efforts on the unmarried. On the reproductive health side, the assumption has been that, once married, girls and boys have access to the same reproductive health services as adult women and men. Yet this may not be the case. For instance, safe motherhood initiatives and HIV/AIDS efforts have generally failed to consider the special situation of young married women (Bruce and Clark 2003; Miller and Lester 2003). Ironically these young brides may comprise one of the largest groups of vulnerable adolescents in the developing world.

Married adolescents tend to be more disadvantaged along a host of social indicators than their unmarried counterparts and slightly older married women (Haberland, Chong, and Bracken 2003). These social indicators may combine with biological factors (related to age, gender, and parity) and patterns of disease transmission to increase health vulnerabilities. For instance, very young first-time mothers may have special maternal health needs (Miller and Lester 2003). In some settings, early marriage may increase girls' and young women's risk of contracting HIV (Bruce and Clark 2003).

The vulnerabilities of married adolescents have not gone altogether unnoticed. In the past, a limited number of projects tried to address the needs of adolescent mothers, though mostly with a focus on motherhood or family planning rather than marital status or the contextual issues accompanying early marriage. More recently, a small number of programmes have been directed explicitly toward married adolescents. This paper focuses on some of those more recent efforts, highlighting innovative programs and describing their evolution and activities.

\section{Schema of the Paper}

This paper provides insight into what is being done — or not being done - to support married adolescent girls and boys, how these populations' needs are being conceptualized, and the extent to which social context is factored into programme design. We first consider some early work with adolescent mothers (married and unmarried). We then briefly examine the degree to which selected adolescent programmes have been able to reach married girls with their activities. We present a few basic parameters of potential interventions for married adolescents, including an inventory of current projects, to examine how, when, and at whom efforts typically are directed. Finally, we present three in-depth examples of recent, ongoing programmes for married adolescent girls.

\section{EARLY WORK: SUPPORTING ADOLESCENT MOTHERS}

Some early programmes addressed certain needs of married adolescent girls. For example, projects in the 1970s and 1980s recognized the vulnerability of adolescent mothers; and while they aimed to serve girls regardless of marital status, their participants in many instances included married young women. For instance, the Women's Centre of Jamaica Foundation 
(WCJF) was initiated in 1978 with the objective of motivating young mothers to opt for education instead of further childbearing. Still in operation today, the programme has offered educational interventions, nutritional education and support, a day nursery, and counselling and referral services out of seven centres and six outreach stations throughout the country. As of 1998 the programme had helped over 22,000 adolescent mothers return to the school system. While data on the percent married are not available, many of those who benefited from the programme were married adolescents. Programme evaluations highlight the success of the WCJF project, revealing clear differences between client and non-client young mothers. For example, a 1988-89 evaluation found that the programme reduced the likelihood of participants'

experiencing a second pregnancy: 14.6 percent of programme graduates compared to 38.7 percent of non-participants had had a repeat pregnancy (McNeil et al. 1989 cited in Barnett et al. 1996). Important lessons learned include the difficulties associated with societal attitudes toward mothers returning to school and the need for dedicated and committed staff (McNeil 1997).

Another example can be found in Mexico, where the Mexican Association for Sex Education (AMES) initiated a programme in 1986. The aim was to provide postpartum family planning information and counselling services to women under the age of 20 who had delivered their babies in a particular Mexico City hospital. Education and services were also provided to the young mothers through a special adolescent clinic in the same hospital. Pregnant girls participated in group sessions and were then visited at their bedside immediately after delivery and encouraged to return to the hospital for a postpartum check-up. A majority of the project participants were married or in consensual unions. In an evaluation, contraceptive use among participants was found to have increased. A key recommendation made following the first phase of the project was the importance of addressing non-health issues in addition to maternal and child health and family planning, and of being sensitive to girls' social context: for example, working more systematically with the young mother's family in order to support her, and helping girls improve their assertiveness skills (Corona et al. 1988).

\section{MOST CURRENT YOUTH INITIATIVES DO NOT REACH MARRIED ADOLESCENT GIRLS}

The two programmes described above (and other similar ones) sought to help pregnant adolescent girls, and, in many settings this implicitly meant working with married girls. By contrast, the majority of other general adolescent reproductive health programmes (those dealing with sexuality education, for example, or pregnancy or HIV prevention) have typically focused on the unmarried. These programmes often work through youth centres, schools, youth-friendly services, and other settings that are more likely to reach the unmarried than the married. Many of these general adolescent projects have made efforts to include all adolescents, regardless of marital or pregnancy status, but it is unclear whether such programmes have succeeded in reaching married adolescents. Indeed, a brief analysis of a subset of Population Council work with adolescents suggests that unless explicit efforts are made to include married adolescents, they may be excluded by default.

We looked at nine programmes located in Bangladesh, Egypt, Ethiopia, Guatemala, India, Kenya, and South Africa. All of these programmes aimed to expand girls' life options and 
improve their reproductive health. Of the nine, three were still in a research phase; their provision for married adolescent needs could only be described in terms of intent. Of the six programmes that had been implemented, three had considered married adolescent girls in the design of the programme. However, none had made special provisions for their inclusion and their special needs. Only one, which was geared toward delaying marriage, explicitly excluded married girls from its programmes; in the rest of the programmes, married adolescent girls were eligible to participate.

Ultimately, in only one of the programmes, the K-Rep micro-finance programme for adolescents in Kenya, did a substantial proportion of married adolescent girls join, comprising 33 percent of participants (Khan, personal communication). In two other programmes, married adolescent girls did join, but in small proportions compared with their representation in the general population. For example, in a micro-credit programme in Bangladesh, the unmarried were 10 times more likely to join than the married (25 percent versus 2.5 percent of the sample) (Amin, Mahmud, and Huq 2002). Similarly, just 4.3 percent of participants in a livelihoods skills and opportunitybuilding programme in India were married (Widge 2003). ${ }^{1}$ Hence, though one of the six implemented programmes achieved a sizable representation of married adolescent girls without making special provisions for their needs, none of the other interventions did. This suggests that even when married girls are not explicitly excluded by adolescent programmes, they often remain beyond their reach.

\section{KEY CONSIDERATIONS FOR MARRIED ADOLESCENT PROGRAMMES}

A variety of factors - including married girls' differing social context and specific health needs - make it imperative to consider married adolescents as a distinct target group when designing reproductive health programmes. Key issues to be taken into account include the temporal point of intervention (or stage in the marital process at which girls and boys can be reached); whether and how girls can be targeted on their own (i.e., removed from relatives and others in their social circles); how to include gatekeepers (such as husbands and in-laws); and the content of the information and services that should be geared toward them.

\section{Points of Intervention: Opportunities in the Marital Transition}

Brady differentiates the various stages at which interventions with married adolescents can take place. She proposes that five phases of the marital transition be considered: not-yet-married (but families are concerned about marriageability), engaged or promised, newly married, married with first pregnancy, and married and postpartum (Brady 2003). When addressing the not-yetmarried, interventions might seek to keep girls in school, increase girls' knowledge of sexual and reproductive health, increase men's sensitivity to women's sexual and reproductive health, and promote gender equitable norms. After the wedding/cohabitation, important areas to address include ensuring healthy transitions to marriage and motherhood, promoting mother and child well-being, and fostering open, egalitarian communication and shared decisionmaking among young married couples. To these stages and corresponding intervention strategies we would also

\footnotetext{
${ }^{1}$ An additional 0.8 percent of participants in this program were divorced or widowed, and 20.5 percent were engaged or married but not yet residing with their marital families.
} 
add widowed/divorced women. Such young women may have distinct and urgent needs regarding livelihoods, social support, and legal rights.

\section{Supporting Girls: Safe and Empowering Spaces}

Gender norms in most societies tend to create situations in which young girls suffer far greater disadvantage than boys. Projects might choose to address this vulnerability by including a component directed separately at girls. Group-based programmes have been successful in increasing elements of women's autonomy and agency (Schuler et al. 1996; Rogow 2000; Arens et al. 2002; Schuler and Hashemi 1994), and may be an effective approach to working with married girls. Bringing girls together - apart from their families, spouses, and partners - to work collectively on community mobilization, development, and/or poverty alleviation activities (such as gender sensitisation or savings and credit groups) may be a powerful means for creating and deepening their peer networks, helping them acquire skills (both economic and negotiating), changing gender attitudes, and strengthening their ability to identify needs and to plan and act for their own interests.

\section{Social and Familial Context: Including Gatekeepers and Changing Norms}

The relative isolation and limited autonomy that characterize married girls' lives in many societies suggest that programmes must pay attention to social and cultural context. For instance, given the central role that mothers-in-law, husbands, and other family members play in married girls' health-seeking behaviour and knowledge, efforts that target these gatekeepers, encourage husbands' involvement, or otherwise affect the gender norms and attitudes prevalent in communities are crucial. For example, emerging work in Brazil is showing not only that traditional attitudes toward masculinity are antecedent to poor sexual and reproductive health, but that they are amenable to change and that changing them may decrease gender violence and increase condom use (Pulerwitz, Barker, and Segundo 2004). Finally, when broadening the target group beyond girls, it is important not to jeopardize whatever fragile spaces and autonomy girls may have carved out for themselves.

\section{Programme Content}

Programmes for married girls might aim to increase reproductive health knowledge, to improve reproductive health services, to further girls' education, and to expand girls' skills, agency, social networks, command over resources, and/or negotiating power in relationships. These goals also can be combined in a multi-faceted approach to improving married adolescents' welfare. Efforts to change traditional gender norms and delay age at marriage could be important complements. Priorities will vary from setting to setting but even in situations where, for example, only health services can be adjusted, those services may be improved by considering married girls' social context. Providers might be trained to consider married girls' mobility in the design of their routine antenatal or postpartum care, to be sure to discreetly solicit and respond to girls' own fertility desires or infection prevention concerns in any "couple counselling," and to know how to handle and support young women who are being physically or sexually abused by their spouse. 


\section{WHAT THE NEW PROGRAMMES FOR MARRIED ADOLESCENTS DO}

As mentioned earlier, a handful of programmes now underway or in their initial stages specifically target married adolescents. To better understand these interventions and how they serve married adolescents' needs, we conducted a rough inventory of their efforts. We collected descriptive information from a review of relevant literature, an extensive internet search, and by contacting the organizations directly and asking them about their married adolescent activities. As a result, we identified 12 programmes in Bangladesh, Brazil, Burkina Faso, Cameroon, India, Nepal, Nigeria, and Pakistan that target married adolescents in some way.

The inventory in Table 1 maps out the different reported programme activities in terms of several general categories. The results for each category are first described in brief. The 12 projects presented are listed in the inventory key (a more detailed list of programmes that includes the full name/s of implementing organization/s can be found in the Appendix).

\section{Categories}

\section{Target Group}

The programmes we inventoried provide services to one or more of the following:

- engaged girls

- newly married girls

- newly married boys

- newly married couples

- first-pregnancy girls

- first-pregnancy couples

- first-birth mothers

- first-birth couples

- family members of married adolescent girls

- girls who were widowed, divorced, or abandoned

\section{Information}

The programmes surveyed provide information to married adolescents on the following topics: HIV, sexual and reproductive health, maternal and child health (which includes information on topics relating to antenatal care, delivery, and postpartum care), family planning, and broader gender-related issues.

Health Services

In addition to information, a few of the organizations surveyed provide services to married adolescents. These programmes generally address issues relating to sexual and reproductive health, maternal and child health, and family planning.

\section{Programmes}

Beyond information and services, a number of programmes also include activities outside the health sector that seek to improve the livelihoods of married adolescents in a broader sense. Programme content includes economic, social, education, and legal issues. 


\section{Modality}

Finally, we examined the means of information/service/programme delivery. Some programmes provide clinic-based services while others carry out home visits, conduct community-wide campaigns, conduct group formation activities, or train peers to assist with information provision and service delivery.

\section{Caveats}

\section{Columns Not Mutually Exclusive}

The categories of programme types in Table 1 are not mutually exclusive; indeed, many programmes provide multi-pronged interventions. For example, some might provide services in a clinic setting, while also distributing information during home visits.

\section{Inventory Not Exhaustive}

Although we sought to identify as many projects working with married adolescents as we could, there are undoubtedly some we did not find. A few others were identified but despite extensive efforts we were unable to obtain the minimum information on the project necessary to include them here.

\section{Programmes Specifically for Married Adolescents}

Only programmes that were specifically designed to serve married adolescents are included in the inventory. We encountered other programmes that served married adolescents, but by default and not by design. We have not included such programmes here.

\section{Observations}

The inventory reveals that most programmes for married adolescents focus on provision of information. All of the programmes surveyed distribute information, many on several of the topics listed above (i.e., HIV, sexual and reproductive health, etc.), and many to a range of target groups at a time. There appears to be a tendency to focus on the newly married, with fewer efforts addressing the needs of the engaged, of those pregnant or postpartum for the first time, and of divorced, widowed, or abandoned girls.

Health services that are specifically designed for or adapted to be sensitive to the special situation of married girls are far less prevalent than information dissemination. Nevertheless, several of the programs, while not themselves including service provision among their activities, do link with existing health services (for example, accompanying girls to antenatal visits, sensitizing providers to the special needs of married girls, etc.). HIV and related care services were not provided in more than a superficial manner by any of the programmes we surveyed, and girls and couples experiencing pregnancy for the first time were not a focus of most of these programmes. In terms of non-health-sector programme efforts, nine of the 12 projects were active in this area to some degree. The bulk of these interventions focus on education and livelihoods, with just two covering legal rights.

Where venue/modality is concerned, none of the programmes utilized media as a means to reach married adolescents. However, given research findings that indicate that married girls in some 
settings have less access to television and radio than unmarried girls (Thapa and Mishra 2003; Amin, Mahmud, and Huq 2002), this may be appropriate. Peer counselling efforts appear to be focused on the engaged and the newly married. About half the projects utilized some type of group formation as a strategy for reaching the target population.

In terms of temporal points of intervention, programmes appear generally to target newly married girls and newly married couples. Special attention during the period of first pregnancy and/or first birth was given less frequently (see below for examples of two that do focus on pregnancy/birth).

Notably, one of the few projects to reach young fathers is the Papai programme, in Recife, Brazil. $^{2}$ The programme provides young fathers and fathers-to-be with opportunities to discuss and reflect upon social and health issues relating to fatherhood and to their reproductive health. Papai's goal is to improve boys' responsibility for their reproductive lives and to assist girls in involving their child's father in the nurturing process. Another goal is to increase awareness of fatherhood among professionals working with adolescent issues. The Adolescent Fatherhood programme operates through two separate mechanisms: workshops and home-visits. Each component specifically targets young and adolescent fathers, and each aims to provide fathers with the opportunity to learn about and discuss fatherhood - including infant care, positively supporting their partner, labor and delivery, and other topics - as well as their own reproductive health, such as prevention of STIs and HIV. Condoms and educational materials are distributed at all meetings, and information on where to obtain free condoms is provided. Also emphasized throughout all programmes is the availability of other health and social services in Recife, including those at the Papai office. Men are repeatedly invited to Papai and encouraged to call or visit with questions. The majority of boys are from low-income homes with minimum-wage earnings or total unemployment. Most have not completed secondary (high) school and many dropped out of school before entering middle school. While participation is low primarily as a result of scheduling problems and young men's limited free time, Papai continues to explore ways to reach boys. It is innovative and noteworthy in its effort to reach highly marginalized boys at a potentially critical transition in their lives.

\footnotetext{
${ }^{2}$ Information on the Papai program was provided by: Jorge Lyra and Daniel Cardoso, personal communication; and Barker, Lyra, and Medrado, 2003.
} 
TABLE 1. AN INVENTORY OF PROGRAMMES FOR MARRIED ADOLESCENTS

\begin{tabular}{|c|c|c|c|c|c|c|c|c|c|c|c|c|c|c|c|c|c|c|c|}
\hline \multirow[b]{2}{*}{ Target group } & \multicolumn{5}{|c|}{ Information } & \multicolumn{4}{|c|}{ Health services } & \multicolumn{4}{|c|}{ Programmes } & \multicolumn{6}{|c|}{ Venue/modality } \\
\hline & HIV & SRH & MCH & FP & Gender & SRH & MCH & FP & HIV & Economic & Social & Education & Legal & $\begin{array}{l}\text { Clinic- } \\
\text { based }\end{array}$ & $\begin{array}{l}\text { Home } \\
\text { visits }\end{array}$ & $\begin{array}{c}\text { Community- } \\
\text { wide }\end{array}$ & Media & $\begin{array}{l}\text { Group } \\
\text { formation }\end{array}$ & $\begin{array}{c}\text { Peer } \\
\text { counseling }\end{array}$ \\
\hline Engaged girls & $\begin{array}{l}\text { ICRW/FRHS } \\
\text { PCBF }\end{array}$ & \begin{tabular}{|l} 
APWA \\
ICRW/FRHS
\end{tabular} & PCBF & APWA & & APWA & & & & APWA & & APWA & & APWA & PCBF & $\begin{array}{l}\text { APWA } \\
\text { PCBF }\end{array}$ & & APWA & $\begin{array}{l}\text { APWA } \\
\text { PCBF }\end{array}$ \\
\hline $\begin{array}{l}\text { Newly married } \\
\text { girls }\end{array}$ & $\begin{array}{l}\text { AHIP ICRW/EH } \\
\text { ICRW/FRHS } \\
\text { PCBF }\end{array}$ & \begin{tabular}{|l|l|} 
AHIP & APWA \\
FTP & \\
HEAL & \\
ICRW/EH & \\
ICRW/FRHS \\
PCBF PF PF
\end{tabular} & \begin{tabular}{|l|} 
AHIP \\
IIRWIEH \\
IIRW/FRHS \\
FTP PCBF \\
PF
\end{tabular} & $\begin{array}{l}\text { AHIP APWA } \\
\text { ICRW/EH } \\
\text { ICRW/FRHS } \\
\text { FTP PF }\end{array}$ & \begin{tabular}{|l|} 
AHIP ICRW/EH \\
ICRWIFRHS \\
FTP
\end{tabular} & $\begin{array}{l}\text { APWA HEAL } \\
\text { ICRW/EH } \\
\text { FTP }\end{array}$ & FTP & PF FTP & & $\begin{array}{l}\text { APWA } \\
\text { ICRWIEH } \\
\text { FTP }\end{array}$ & \begin{tabular}{|l} 
FTP \\
ICRWIEH
\end{tabular} & \begin{tabular}{|l|} 
AHIP APWA \\
HEAL \\
PCBF
\end{tabular} & FTP & $\begin{array}{l}\text { APWA } \\
\text { FTP } \\
\text { RUWSEC }\end{array}$ & \begin{tabular}{|l|} 
ICRW/FRH \\
S FTP \\
HEAL \\
PF \\
PCBF \\
\end{tabular} & $\begin{array}{l}\text { APWA } \\
\text { ICRW/EH } \\
\text { ICRW/FRHS } \\
\text { FTP } \\
\text { HEAL } \\
\text { PCBF }\end{array}$ & & \begin{tabular}{|l|} 
APWA \\
ICRWIFRHS \\
FTP \\
HEAL \\
PFF
\end{tabular} & \begin{tabular}{|l} 
APWA \\
HEAL \\
ICRW/EH \\
PCBF
\end{tabular} \\
\hline $\begin{array}{l}\text { Newly married } \\
\text { boys }\end{array}$ & $\begin{array}{l}\text { AHIP ICRW/EH } \\
\text { ICRW/FRHS } \\
\text { PAPAI } \\
\end{array}$ & \begin{tabular}{|l|l|} 
AHIP & ICRW/EH \\
ICRW/FRHS \\
FTP & UNFPA \\
PAPAI & \\
\end{tabular} & \begin{tabular}{|l|l|} 
AHIP ICRW/EH \\
ICRW/FRHS \\
FTP \\
PAPAl
\end{tabular} & \begin{tabular}{|l|} 
AHIP ICRW/EH \\
ICRW/FRHS \\
FTP PAPAI \\
\end{tabular} & $\begin{array}{l}\text { AHIP ICRW/EH } \\
\text { ICRW/FRHS } \\
\text { FTP PAPAI }\end{array}$ & ICRW/EH & & & & $\begin{array}{l}\text { ICRW/EH } \\
\text { UNFPA }\end{array}$ & \begin{tabular}{|l|} 
UNFPA \\
ICRW/EH
\end{tabular} & AHIP UNFPA & & & \begin{tabular}{|l|} 
ICRW/FRH \\
S \\
FTP \\
PAPAI
\end{tabular} & ICRWIEH & & \begin{tabular}{|l|} 
ICRW/FRHS \\
UNFPA
\end{tabular} & $\begin{array}{l}\text { ICRW/EHUNFP } \\
\text { A }\end{array}$ \\
\hline $\begin{array}{l}\text { Newly married } \\
\text { couples }\end{array}$ & RUWSEC & \begin{tabular}{|l} 
FTP \\
PF \\
RUWSEC
\end{tabular} & $\begin{array}{|ll|}\text { FTP } & \text { PF }\end{array}$ & $\begin{array}{|ll|}\text { FTP } & \text { PF } \\
\text { RUWSEC } & \\
\end{array}$ & \begin{tabular}{|l} 
FTP \\
RUWSEC
\end{tabular} & & PF & $\mathrm{PF}$ & & PF RUWSEC & RUWSEC & & & & PF & RUWSEC & & PF RUWSEC & \\
\hline $\begin{array}{l}\text { First-pregnancy } \\
\text { girls }\end{array}$ & $\begin{array}{l}\text { ICRW/FRHS } \\
\text { PCBF }\end{array}$ & $\begin{array}{|ll|}\text { ICRWIFRHS } \\
\text { FTP } & \text { PCBF } \\
\end{array}$ & $\begin{array}{|ll|}\text { ICRW/FRHS } \\
\text { FTP } & \text { PCBF } \\
\end{array}$ & \begin{tabular}{|l|} 
ICRW/FRHS \\
FTP
\end{tabular} & \begin{tabular}{|l|} 
ICRWIFRHS \\
FTP
\end{tabular} & FTP & FTP & & & & FTP & PCBF & FTP & FTP & 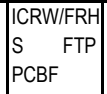 & $\begin{array}{l}\text { ICRW/FRHS } \\
\text { FTP }\end{array}$ & & \begin{tabular}{|l} 
ICRW/FRHS \\
FTP
\end{tabular} & \\
\hline $\begin{array}{l}\text { First-pregnancy } \\
\text { couples }\end{array}$ & & FTP & FTP & FTP & FTP & & & $\mathrm{PF}$ & & & & & & & & & & & \\
\hline $\begin{array}{l}\text { First-birth } \\
\text { mothers (incl. } \\
\text { postpartum) }\end{array}$ & $\begin{array}{l}\text { ICRW/FRHS } \\
\text { PCBF }\end{array}$ & \begin{tabular}{|l|} 
ICRW/FRHS \\
FTP
\end{tabular} & \begin{tabular}{|l} 
ICRW/FRHS \\
FTP $\quad$ PCBF
\end{tabular} & $\begin{array}{l}\text { ICRW/FRHS } \\
\text { FTP }\end{array}$ & \begin{tabular}{|l} 
ICRW/FRHS \\
FTP
\end{tabular} & FTP & FTP & FTP & & & FTP & PCBF & FTP & FTP & \begin{tabular}{|l|} 
ICRW/FRH \\
S \\
FTP \\
PCBF \\
\end{tabular} & $\begin{array}{l}\text { ICRW/FRHS } \\
\text { FTP }\end{array}$ & & $\begin{array}{l}\text { ICRW/FRHS } \\
\text { FTP }\end{array}$ & \\
\hline $\begin{array}{l}\text { First birth } \\
\text { couples }\end{array}$ & |ICRW/FRHS & FTP & FTP & FTP & FTP & & & & & & & & & & & & & & \\
\hline $\begin{array}{l}\text { Family members } \\
\text { of married } \\
\text { adolescent girls }\end{array}$ & $\begin{array}{l}\text { ICRW/FRHS } \\
\text { PCBF }\end{array}$ & \begin{tabular}{|l|l|} 
ICRW/EH & \\
ICRW/FRHS & \\
FTP & \\
PF & PCBF \\
\end{tabular} & $\begin{array}{|ll|}\text { ICRW/FRHS } & \\
\text { FTP } & \text { PF } \\
\text { PCBF } & \\
\end{array}$ & \begin{tabular}{|l|} 
ICRW/FRHS \\
FTP PF
\end{tabular} & $\begin{array}{l}\text { ICRW/FRHS } \\
\text { FTP } \\
\text { PF ICRW/EH }\end{array}$ & & & & & & ICRW/EH & & & & \begin{tabular}{|l|}
$\mid$ ICRW/FRH \\
S FTP
\end{tabular} & \begin{tabular}{|l} 
ICRW/EH \\
ICRW/FRHS \\
FTP \\
PCBF
\end{tabular} & & ICRW/FRHS & \\
\hline \begin{tabular}{|l|} 
Divorced, \\
widowed, or \\
abandoned girls
\end{tabular} & $\overline{\mathrm{AHIP}}$ & AHIP & AHIP & AHIP & AHIP $\quad$ ALVF & & & & & $\overline{\text { ALVF }}$ & ALVF & AHIP ALVF & ALVF & ALVF & & & & ALVF & ALVF \\
\hline
\end{tabular}

$\underline{\text { KEY }}$

Organizations

AHIP: Adolescent Health \& Information Projects; Nigeria

APWA: All Pakistan Women's Association; Karachi, Pakistan

ALVF: Association to Eradicate Violence Against Women; Cameroon

FTP: First-Time Parents Project, CINI, DCT, Population Council; India

HEAL: Heal Trust; Lahore, Pakistan

ICRW/EH: ICRW and EngenderHealth with local organizations; Nepal

ICRW/FRHS: Foundation for Research in Health Systems with ICRW; India
PAPAI: Papai Institute; Brazil

PCBF: Population Council with local partners; Burkina Faso

PF: Pathfinder; Bangladesh

RUWSEC: Rural Women's Social Education Center; Tamil Nadu, India

UNFPA: UNFPA; Bangladesh
Categories

HIV. HIVIAIDS and related

SRH: Sexual and reproductive health

MCH: Maternal and child health; includes antenatal care, delivery, and postpartum services FP: Family planning 


\section{IN-DEPTH PROFILES}

An in-depth examination of three of the programmes for married adolescents follows. Each profile presents information on how the intervention evolved, details of current project content, and expected outcomes and emerging lessons. Two of the programmes profiled here are located in India: the First-Time Parents Project and the Community-Based Approach to Married Adolescent Girls' Reproductive Health Project. The third, the Adolescent Health and Information Projects' vocational training centre, is located in Nigeria.

\section{Profile 1: First-Time Parents Project ${ }^{3}$}

The Population Council's First-Time Parents Project aims to improve married adolescents' reproductive and sexual health knowledge and practices, and to increase their ability to act in their own interests, through a focus on the first birth. It is based on the hypothesis that the period surrounding new marriage and first birth, though a period of vulnerability, offers a unique and influential entry point into improving the prospects of young married women/mothers. The project is conducted in two sites, Vadodara, Gujarat and Diamond Harbour, West Bengal, in partnership with two local nongovernmental organisations (NGOs): Deepak Charitable Trust (DCT), and the Child in Need Institute (CINI), respectively.

The project grew out of the Council's policy research at the global and regional level that identified married adolescent girls as potentially highly vulnerable, and likely underserved. A preliminary assessment of adolescent programmes in India found that most had focused primarily on unmarried adolescents. Yet one-third of 15-19-year-old girls - and the vast majority of sexually active adolescent girls - in India are married. Married adolescent girls are a neglected and vulnerable subpopulation within the gender and age hierarchies prevalent across India. They often have little say in the choice of their marriage partner, are rarely involved in household decisionmaking, and are granted very little mobility. They face enormous pressure to prove their fertility; consequently early childbearing is the norm among married adolescents.

Project partners were identified who had a strong history of community-based health work, shared a common interest in testing interventions that would better meet the needs of married young women, and were open to working on issues outside of the health sector, including social issues.

\section{Origins of the project}

To guide intervention design, a qualitative diagnostic study was completed in both project sites. It consisted of in-depth interviews with young women in the last trimester of a first pregnancy or up to four months postpartum. Interviews were also conducted with young men whose wives were pregnant or postpartum for the first time, senior women (mothers-in-law, mothers, or other influential older women in the household), young women with one or (preferably) two children whose younger child was one or two years old, and health care providers.

In addition to detailing married girls' isolation and limited autonomy, key findings emerging from the diagnostic research included:

\footnotetext{
${ }^{3}$ The information and data for this section were obtained from Santhya and Haberland, 2003.
} 
- Marriage is a gradual transition, and the bride moves relatively frequently between her natal and marital homes following her marriage.

- Young women often return to their natal homes for the delivery of their first baby.

- Postpartum isolation is widespread.

- Although the mother-in-law typically is a powerful force within the family, sometimes young husbands make an effort to support their wives' views within the family, even when they conflict with their mothers' ideas.

- A number of young men and women would have liked to delay their first birth, but did not know how, did not know how to discuss delaying it with their spouses, or felt pressure from family, community, and peers to have a baby soon after they married. A strong desire to space the second pregnancy was also evident.

- The importance of antenatal care is widely known and accepted, and virtually everyone uses antenatal services to varying degrees. However, few are able to plan for delivery, and there are limited postpartum services for women.

On the basis of these findings, the Council worked collaboratively with its NGO partners to develop comprehensive interventions. The interventions target not only married girls (including newly married young women, young women pregnant for the first time, and postpartum firsttime mothers), but also the husbands of these young women, mothers and mothers-in-law, health care providers, and the community at large. The interventions - operating now for about two years in 12 villages each in West Bengal and Gujarat - consist of three main elements: information provision, health care services, and group formation activities. The interventions are tailored to the unique characteristics of each population and the comparative strengths of the NGO partners.

\section{Project activities}

The activities described here focus exclusively on the intervention in West Bengal with the Child in Need Institute (CINI).

\section{Information}

A primary focus of the intervention is to provide women directly with the information they need. The diagnostic study indicated that married girls/young women mostly are reliant on other family members, especially husbands and mothers-in-law, for information, and that that information was often mistaken. Thus, in the intervention, women may receive information through home visits conducted by community health workers, counselling sessions given by providers in clinic settings, discussions that take place in young mothers' meetings, group formation exercises, community activities such as health fairs, and celebrations of health days or health weeks, such as breastfeeding week.

The project staff has been trained on reproductive health topics and on how to promote effective dialogue with the project beneficiaries on these topics. Training is conducted mainly by CINI's training centre, though occasionally outside experts are drawn on to facilitate specific sessions.

Information is conveyed to men through home visits to young husbands by a male health worker, as well as via discussions in monthly neighbourhood meetings of husbands organized to discuss 
specific reproductive health topics. Interactions with mothers-in-law, mothers, and other senior women are also sought so as to relay accurate information to them.

The information provision component of the intervention also has included selection and development of information, education, and communication (IEC) materials as well as new dissemination and counselling techniques. Workshops were organized by project staff and CINI's training centre to review existing IEC materials and to identify gaps in content and philosophy. For instance, to better craft messages for couples, the training centre brought in young couples from the project area to help develop and clarify messages surrounding a variety of maternal health and family planning issues. Some materials were maintained and others newly developed. Information conveyed through the project includes topics such as transmission and prevention of reproductive tract infections; contraception; women's fertility cycle; sex as a voluntary, safe, and pleasurable experience; developing a delivery plan; care during pregnancy and the postpartum period; breastfeeding; and how the husband can be supportive during this time.

\section{Services}

As part of the service component of the intervention, most government and private health service providers (the private providers are mostly unqualified, but much sought-after) in the CINI project sites have been trained by CINI staff on working with married adolescents, married girls' special situation, and opportunities and challenges of first births. In addition, refresher training has been provided for traditional birth attendants on safe delivery, and traditional birth attendants are being ensured a supply of safe delivery kits. Finally, home visits from a health worker are provided to the mother and baby at two to six weeks postpartum, with follow-up visits thereafter. During these visits the health worker asks the woman how she is feeling, answers any questions she may have, helps to ensure that breastfeeding is going well, and counsels on nutrition, selfcare, infant care, and return to sexual activity, among other things.

\section{Group formation}

Another component of the intervention has focused on empowering married adolescent girls/first-time mothers through group formation. Project staff who facilitate the group formation and other social networking activities have participated in training workshops conducted by Nishtha, a local group that works on women's empowerment in West Bengal. The aim of the groups is to increase married girls' contact with peers and mentors, expose them to new ideas, and help them to identify issues that they are concerned with and to act on them. The hypothesis is that these types of empowering activities will increase girls' ability to act on their own behalf in their relationship with their husband and within and outside their family.

To date, 400 girls have been formed into 42 groups in the CINI project sites. The groups take a participatory learning approach and cover topics such as legal literacy, vocational skills, pregnancy and postpartum care, available local resources (e.g., government schemes that women can access; public amenities), gender dynamics within and outside the family, relationship issues, and nutrition. Ideas for topics and activities are identified by the girls themselves, and thus the topics constantly evolve in response to their perceived needs. Most of the training is carried out by the community organizers; however, for specialized topics such as vocational skills or savings and credit management skills (a need identified by the participants themselves), 
local resource persons, especially from NGOs that provide such training, are brought in. The groups typically meet twice a month, with sessions lasting approximately two hours. Meetings, which often take place at local youth clubs, in primary schools, or on the verandas of group members' houses, are normally held in the afternoon, after the group members have finished their household chores. In addition to meetings, the girls in the groups visit places such as the village administrative office, the bank, the post office, and organizations where women's groups are active. They work together on development projects; for instance, some groups have identified laying bricks on the village road as a community activity and have approached the Panchayat for assistance. They also celebrate common festivals and organize welcome ceremonies for newly married members.

To recruit girls to the groups, community organizers and female health workers conducted home visits to all of the target beneficiaries in the intervention area and spoke with them about group formation. They also organized informal neighbourhood meetings in which small groups of young women were invited to hear about project activities. Similarly, home visits and meetings with mothers-in-law were carried out by the health workers and community organizers. In cases where a young woman was interested in participating but experienced objections from her husband, the community organizers have, at times with the help of a male health worker, approached the husband and convinced him to allow his wife to join in the group activities. Or, if it was the mother-in-law who was resistant, they have approached mothers-in-law or sought the help of supportive peers such as a sister-in-law.

\section{Community involvement}

To create a supportive and sustainable environment for the interventions, project staff have conducted group meetings in villages to provide information about the diagnostic findings and solicit input regarding the intervention plans. Ongoing contact between local Panchayat officials and the project supervisor also helps maintain communication and feedback between the community and the project. Additional community-level meetings are held every six months to share project experiences with community leaders.

\section{Monitoring and evaluation}

A quasi-experimental research study with control and intervention villages has been designed to analyse the effects of the interventions. A quantitative survey was conducted at baseline and will be conducted at the conclusion, approximately 24 months after the interventions were initiated. Evaluation questions cover such topics as reproductive health knowledge, power/agency among first-time mothers regarding reproductive health decisionmaking and action, contraceptive use, health-seeking behaviour, partner communication and support, and social networks. In the Gujarat site 1,114 interviews were conducted at baseline, and in West Bengal 1,039 interviews were completed. In addition, ongoing monitoring of the interventions entails routine review of programme records. DCT and CINI project monitoring staff were trained to collect and enter monitoring data and to generate reports regularly.

\section{Observations and challenges}

Some lessons can be learned from challenges encountered over the course of the project thus far. For instance, it is important to address social context issues, to consider that young mothers or 
mothers-to-be in these settings tend to migrate between their marital and their natal homes, and to target husbands in addition to girls.

\section{Addressing social context}

There has been a need to help NGOs traditionally focused on health services to consider and address social context issues. To support the group formation aspect of the interventions, the Population Council has collaborated closely with both DCT and CINI in strengthening staff capacity to work in this area. In the case of CINI, a productive partnership was formed with Nishtha.

\section{Considering target population mobility}

Another challenge relates to the customary movement of young women to their natal home to give birth and recuperate postpartum, particularly after the first birth. This issue was highlighted by the diagnostic research, and three types of female clients were specified: those who would leave the project site (their marital village) to return (often in the last trimester of pregnancy) to their natal home; those who returned to the project site (their natal home) late in their pregnancy to deliver and recuperate postpartum; and those who would remain in their marital home (the project site) to deliver. The intervention is designed to take into account the effects of this movement as much as possible - for instance, by getting health information directly to the woman herself, including strategies such as making a birth plan, and accepting women into the project at any point in their pregnancy and up to one year postpartum. The project is monitoring this approach and will be able to track differential exposure.

\section{Involving men}

Finally, reaching the husbands of the married girls/young women required flexibility and adaptation. It quickly became clear that, as implemented, the home visits to men were not sufficient. To overcome this, neighbourhood meetings of young husbands were organized. In addition, male health workers were encouraged to carry out their activities in the late afternoons or in the evenings when men were more likely to be home.

\section{Profile 2: Community-Based Approach to Married Adolescent Girls' Reproductive Health Project ${ }^{4}$}

The Community-Based Approach to Married Adolescent Girls' Reproductive Health Project is being implemented by the Foundation for Research in Health Systems (FRHS) and the International Center for Research on Women (ICRW) in Ahmednagar district, in the Indian state of Maharashtra. FRHS is an independent group of professionals from a variety of disciplines who conduct scientific and social research aimed at improving India's health systems. The project's goal is to test the relative effectiveness of two approaches to improving the reproductive health of married adolescent girls. One approach provides girls with reproductive health education and counselling through community-based organizations (CBOs), also targeting the girls' husband and mother-in-law. The second approach aims to improve the quality and content of public sector services by training government health service providers.

\footnotetext{
${ }^{4}$ The data and information for this section were provided by Rohini Pande, personal communication; and Barua and Kurz 2001.
} 


\section{Origins of the project}

The project evolved from a series of FRHS studies. The first, a baseline situation analysis conducted in 1994, examined married women of reproductive age (15-49 years old). Study results indicated that married adolescent girls had poorer knowledge and lower utilization of primary health care services than older women. Before the study, government health officials in the district had considered all married women of reproductive age to be equally vulnerable, and assumed that younger women were able to access services as easily as older women. The findings from the study suggested that this was not the case, however, and led FRHS to probe further into the situation of married adolescent girls. They hypothesized that the observed unequal access was derived from girls' low position within their marital family and that, with little or no decisionmaking power, their ability to seek out health care depended entirely on their husband's and/or other family members' perception of their health needs.

This hypothesis served as the basis for a second study, conducted between 1996 and 1998 in the same area, which sought to understand how married adolescent girls and their family members perceive reproductive health needs, and how these perceptions influence girls' likelihood of getting care. Findings revealed that, by and large, young girls as well as their husbands and mothers-in-law viewed childbearing as a normal physiological phenomenon with negligible associated risks. The common opinion on gynaecological problems, such as vaginal discharge or prolapse, was that they were an unavoidable - and not particularly worrisome - aspect of being a woman. As a result, whereas more than half of the married girls surveyed (51 percent) reported suffering from gynaecological problems, only half of those who had experienced problems reported having sought treatment for them. Young women were either unaware that their problems were treatable or had been discouraged by family members from mentioning their condition. Qualitative data revealed that husbands generally believed that their own involvement in pregnancy-related care was unnecessary and were generally ignorant of women's illnesses; those who were aware of problems, however, were found to have encouraged their wives to seek treatment. Mothers-in-law, though more aware of the types of problems girls might face, generally endorsed traditional treatments, many of which were inconsistent with modern medicine.

\section{Project activities}

On the basis of these findings, FRHS and ICRW developed a multi-pronged intervention to address married adolescent girls' needs and to improve their access to health care: the Community-Based Approach to Married Adolescent Girls' Reproductive Health Project. Working with women, their families, and the community, project staff seek to create both an awareness of and demand for services, and to ensure that the health system is capable of meeting the increased demand that is likely to result from the intervention.

\section{Strengthening existing institutions}

Underlying the entire project is a commitment to strengthening existing institutions rather than creating new ones. Many activities are carried out through a network of community-based organizations that work in rural Maharashtra. The region in which FRHS operates has a rich history of indigenous CBO formation. Groups active at various levels provide cultural and social development services and activities to all sectors of the population. CBOs include those formed 
specifically to implement government programmes (such as savings or adult literacy programmes), income-generation activities, youth clubs, sports clubs, women's or men's clubs, and many others. FRHS works with these existing groups, helps strengthen their capacity, and provides participants with health education, information, and counselling (described below), often at the locations that the CBOs occupy.

Working through these existing CBOs, as well as through government health service systems, the married adolescent project includes several main components:

\section{Health education and counselling sessions with married adolescent girls}

This first component consists of interactive group sessions carried out by trained staff, including government health personnel and FRHS staff. Even though adolescent girls are the primary target of these sessions, women of all ages participate, including adolescent girls' mothers, mothers-in-law, and other women from the community. There are three reasons for this: 1) project managers believe that wider participation will foster community support for adolescent needs, a fundamental programme goal; 2) the government of India has stipulations against agebased discrimination; and 3) adolescents in a patriarchal and hierarchical society such as India's may be best reached through their elders, which requires gaining the confidence of those elders.

Sessions cover a wide variety of reproductive and sexual health issues, ranging from menstruation to maternal health, sexually transmitted infections, HIV, and family planning. Meetings are independent of regular CBO activities and are convened during times when no other $\mathrm{CBO}$ activity is taking place. CBO members are alerted and invited to upcoming meetings; and while $\mathrm{CBO}$ personnel assist with convening the meetings, participation in the sessions is open to all women in the village. Therefore, whereas the proportion of married adolescent girls in women's CBOs is less than 10 percent of participants, their participation in FRHS activities is much higher, ranging from 25 to 33 percent. Meetings are organized to cover three reproductive and child health topics per three-month cycle, and topics are chosen from a list reflecting the government of India's reproductive and child health $(\mathrm{RCH})$ essential service package.

Sessions are advertised through government sub-centres as well as village-based FRHS personnel who announce upcoming sessions during regular house visits. Reminder visits also often take place on the day of the session. The number of participants in each session ranges from 15 to 50, and typically 95 percent are married. Information given to participants includes how the sex of a baby is determined by male chromosomes; important health-related issues, including common misconceptions and traditional beliefs regarding women's reproductive health; and gender issues, such as male involvement in women's health. Information is conveyed through lectures, participatory methods, and IEC materials.

\section{Health education and counselling sessions with gatekeepers}

A second programme component targets husbands and mothers-in-law of married adolescent girls with interactive sessions that aim to sensitize these "gatekeepers" to sexual and reproductive health and other issues faced by the young women. As described above, mothers-inlaw participate in the same sessions as the girls, but separate sessions are convened for husbands. Men's sessions are organized similarly, and recruitment processes are the same as those used for female sessions. However, additional "male-specific" information is also provided. For example, 
emphasis is placed on the importance of allowing women to rest, particularly during pregnancy, on the need for better nutrition for women, and on supporting women's emotional needs and health care seeking.

\section{Training government health providers}

The aim of this programme component is to improve government health providers' responsiveness to the sexual and reproductive health needs of married adolescent females. Trainees are provided with information on health issues particularly relevant to married girls as well as instruction on communication and counselling with young women and their families. Experts in the field are invited to attend as resource persons. Sessions take place every three months and last for two days; they are provided in addition to the regular training received by government officials/staff. All of the staff from the government centres in both study areas receive training together.

\section{Providing information and referrals}

The programme also provides communities with the information they need to better access existing health services for young married couples. Information is provided to young women and their families on where relevant services are available for different health care situations. For example, delivery cases are generally referred to a sub-centre; however, it is stressed that more difficult deliveries should be performed at the district hospital. This effort is made in order to prevent local communities from growing disillusioned with the quality of care available at local centres. Referral cards are not given at these sessions, but FRHS staff do on occasion accompany women to the referral place.

\section{Monitoring and evaluation}

A rigorous monitoring and evaluation system is in place to assess these activities and the impact of the programme as a whole. Baseline, mid-point, and end-line random surveys of married adolescent girls and their husbands have either been completed, are being conducted, or are planned. In addition, programme activities are monitored on an ongoing basis, using protocols that measure frequency of health education sessions; attendance at sessions; training frequency and quality for government staff; as well as community evaluations of FRHS staff, health education sessions, and government services. These data are computerized so that data entry in the field offices is linked to the head office for immediate analysis, feedback, and programme changes. These quantitative data are supplemented by periodic qualitative analyses, such as interviews with mothers-in-law about their attitudes and support of the reproductive health of their adolescent daughters-in-law. To test whether there are differential and/or synergistic effects of the components, there are four cells: improving government health systems only; social mobilization through CBOs only; both strategies combined; and a control area. In addition, a cost analysis will be conducted.

In terms of expected outcomes, it is hoped that the programme will positively affect the knowledge and awareness of a variety of sexual and reproductive health issues among young married women, their husbands, mothers-in-law, and communities. Attitudinal changes are also expected among husbands and mothers-in-law toward married adolescent girls' sexual and reproductive health problems and the need to address them, as well as in community attitudes about the acceptability of discussing and addressing young married women's needs. The degree 
to which young married women are empowered in their sexual and reproductive health is expected to increase, as is the extent to which girls discuss with their husbands and their mothers-in-law decisions about age at first birth, numbers of children, contraceptive use, and health-seeking behaviour. With regard to government services, changes are expected in the degree to which adolescent needs are responded to, and in the ability of government staff to counsel and communicate with young married couples seeking care.

\section{Observations and challenges}

At present, the project is more than half-way complete. Several observations and lessons regarding outcomes and process can be discussed at this stage.

\section{The need to incorporate participants' input into programme content}

FRHS regularly updates its programme design according to feedback from participants. For example, older women requested that counselling sessions be more interactive, whereas younger women requested more didactic methods; in response to these requests, sessions vary in method according to the proportion of participants who fall into any one age-group. This process also allows community members to take ownership of issues, as evidenced by many cases where $\mathrm{CBO}$ members have approached FRHS to request additional services, information, and assistance.

\section{The need to discuss reproductive health in sufficient detail}

Programme participants were generally aware of basic reproductive and maternal health information; however, they were less knowledgeable about details. For example, most husbands were aware that precautions are necessary during delivery, but few knew all the precautions that should be taken.

\section{Men want to participate in their wives' reproductive health}

Young husbands were concerned about and wanted to participate in their wives' health care seeking, at least in terms of maternal care (data for other health outcomes are yet to be analysed). However, men were generally prevented from doing so by traditions that teach the unacceptability of men's participation in maternity issues. Health system attitudes and conditions also contribute to men's failure to participate. For example, the lack of privacy in clinics discourages participation by men who already feel shy about involving themselves in their wives' reproductive and maternal health care.

\section{Government health personnel want to learn how to better serve these groups}

Government functionaries at the district and particularly at the local (village) levels in the project area have been eager for additional training. They are aware that a large number of their prospective clientele are young couples and are uncertain about how to interact with them. This is evidenced by their unprompted demand to expand training services in counselling and communication with young married couples to other geographic areas. Being involved in the implementation process has given government health service personnel a sense of ownership, something that past project experience has shown to be important in fostering mainstream integration and sustainability. 
Profile 3: Adolescent Health and Information Projects' Vocational Training Centre ${ }^{5}$

Adolescent Health and Information Projects (AHIP) is a nongovernmental organization in northern Nigeria that develops and implements programmes for women and young people. Established in 1989 as a children's recreational centre and restructured in 1992 to its current format, AHIP focuses on health, social, and economic issues. AHIP informs its programmatic agenda through action research, and has conducted research on such topics as young people's sexual behaviour and gender relationships. Projects are implemented through headquarters in the city of Kano and two branch offices in rural parts of Bauchi and Jigawa states, as well as through partners in other areas of Nigeria.

AHIP programmes include sports, youth clubs, vocational training centres, and in-school projects. For instance, AHIP's efforts to promote young people's physical development and leisure time through sports have led over the years to three strong basketball teams and a project for soccer that has over 100 members. The focus of this profile is on an AHIP vocational training centre in Kano. Established in 1995, the centre provides vocational training for out-of-school adolescent girls and boys, 75 percent of whom are either married or divorced (and 95 percent of whom are female). Participants are instructed in vocational and income-generation skills such as tie-dye, knitting, sewing, soap and pomade making, handicrafts, and small-scale business management. They are also instructed in basic literacy, health education, home management, and the fundamentals of human rights law.

\section{Origins of the project}

The training centre began as a youth club in which recreational activities were organized for a small group of unmarried adolescents. The club's membership grew quickly, and activities evolved to incorporate sexual and reproductive health education. This growth attracted the attention of the community, eliciting a harsh reaction to the club's new focus on sexual and reproductive health - a subject deemed inappropriate and unnecessary for adolescents. The community's reaction forced AHIP to reevaluate both itself and the needs of the community, a process that led to the creation of the training centre.

AHIP's reevaluation, while informal, involved both advocacy and discussions with various individuals and groups in the community. Parents and teachers of youth club children who recognized the benefits of the clubs reiterated to the community the importance of AHIP's work. At the same time, discussions were held between AHIP staff and traditional/religious leaders, parents, and teachers to gauge general opinion on AHIP activities, to determine what people believed AHIP's role ought to be, and to ask advice on how best to assume that role. The media were explicitly avoided during this process because AHIP worried that involving them might only aggravate people's concerns about sexual and reproductive health and young people, and that the media might emphasize only traditional myths relating to sexual and reproductive health.

AHIP's reevaluation revealed a need to focus on issues relating to early marriage. It had become evident that early marriage, while widely practiced, was a source of great discontent in the community, resulting in widespread abuse of girls and high rates of divorce. Some young women, for example, were found to have been married and divorced three times by the time they

\footnotetext{
${ }^{5}$ The information and data for this section were provided by Ms. Mairo Bello, personal communication.
} 
were 25 years old, having suffered mental and physical abuse during each marriage. Because coping with and recovering from these situations was difficult, divorced girls were also a source of emotional and economic stress for parents and families. As a result, AHIP decided to reorient its youth club activities to address the issue of early marriage and to cater to the needs of married adolescents.

The vocational training centre was established in 1995 on the assumption that married young people who are empowered with life skills will be better able to negotiate for their rights and to participate in family, community, and societal decisionmaking. These empowered youth will also understand when and how to seek medical care, particularly for sexual and reproductive health issues. Moreover, adolescents who are unmarried, as well as those who are divorced, will have the tools to delay marriage and/or to cope with divorce.

\section{Project activities}

The AHIP training centre aims to empower married, unmarried, and divorced adolescents by training them in income-generation skills and educating them on human rights issues, health, and home and financial management. The recruitment process and details of the classes and participants are provided below.

\section{Recruitment}

Participants hear about the training centre by word-of-mouth and public announcements and approach the centre indicating their interest in acquiring skills. Applicants must purchase an application form (proceeds go toward replication of the form), complete it, and submit it along with a signed letter from parents, husbands, or guardians. The letter serves to obtain and reinforce gatekeepers' support for participants - boys and girls — attending the training, completing all required coursework, and abiding by all centre rules and regulations.

Once enrolled, participants are divided into groups of 30 according to gender and the skills they wish to acquire. Adolescent girls receive training from women and boys from men. Vocational skills instruction is provided by hired teachers, and health classes are taught by AHIP staff. A typical weekly schedule involves vocational skills training from Monday through Thursday, and either a course in home management (for girls) or additional skills training (for girls or boys) on Fridays. Two mornings a week, health education classes are given. Participants typically sign up for a six-month course and then in many instances continue for another six months to learn other skills. A typical graduate attends the centre for a year. Participants reside at home during their participation, attending the centre from 9 a.m. to 1 p.m., Monday through Friday.

Thus, students spend a sizable amount of time at the centre during their course term. When asked what motivated parents - girls' parents, in particular - to allow their children to attend in spite of the time commitment involved, an AHIP official said parents are aware that acquiring skills will empower their daughters and help them earn respect from future or current husbands and inlaws. This awareness makes parents willing to allow their children to attend classes. Husbands, in turn, are believed to see the time commitment as a positive investment toward their wife's contributing financially to the family or more capably managing the home. 


\section{Vocational skills}

As mentioned, vocational skills are imparted to girls and boys separately. Girls typically sign up for handicrafts production classes and also take cooking classes so as to be able to sell prepared food. Boys typically select classes in tailoring, welding, and carpentry. All participants receive basic instruction in small-business management. This includes financial management and basic book-keeping, for example how to record stocks, monitor sales, price goods, reinvest surplus, and use capital wisely. Students also learn how to package and market products.

\section{Health education and human rights}

In addition to the skills training that participants receive, they are also instructed in subjects relating to health and basic human rights. Health classes cover topics such as personal hygiene and body care, sexual and reproductive health, contraception, STIs, HIV/AIDS, and baby and child care. Sexual and reproductive health instruction covers topics such as negotiating skills (especially with regard to sex), self-examination, pre-, post-, and neonatal issues, and cancers related to the reproductive tract. The importance of seeking early treatment for ailments is also stressed. Human rights classes instruct women about their social rights, including their right not to undergo female genital cutting/female genital mutilation, about their rights in and out of marriage, and about their rights over their bodies. Courses for young men stress the importance of respecting women's rights. Both girls and boys are taught how to protect themselves under civil and Islamic Shari’a law.

All courses are taught using a participatory, interactive approach.

\section{Participants}

Since 1995, the centre has provided training to over 8,000 adolescents, with an estimated 900 graduates each year. Approximately 100-150 students, all between the ages of 10 and 25 years, sit in each level at a given time, and there are three levels of students in every six-month period. Girls and boys are taught separately at all times, in part because some of the girls are married and therefore not permitted to interact with men outside of their families. As described above, a typical class has 30 students. Students might enrol to learn how to cut clothes, for example, or how to operate a sewing machine. A "term" is 6 months and it usually takes a minimum of two terms to master a skill. Typically, once students have mastered the skill and the term is over, they leave.

The AHIP Training Centre's high rates of attendance are in part the result of their constant advocacy efforts. Instructors advertise the programme at every opportunity, often announcing centre activities at marriages or naming ceremonies, or participating in trade fairs where they display centre achievements. Graduation ceremonies are held for each class, and these attract local attention to the centre and its students. Local government officials are also regularly invited to the centre, where they are celebrated and praised, and often give speeches, thus attracting further attention to the centre.

\section{Working with married adolescents}

At times, AHIP has had to advocate with husbands and/or in-laws to allow young women to continue with their coursework. In some instances, wives are made to quit the programme because their husbands learn about the sexual and reproductive health course content and 
consider it culturally or religiously inappropriate. On other occasions, girls are instructed to stop attending classes because husbands or in-laws believe they will lose control over the girl as a result of the skills she will acquire. In these situations, AHIP staff approach the members of the family and try to convince them to allow the girl to remain in the programme. They remind family members of the benefits the whole family will enjoy as a result of skills training. In most cases, AHIP prevails and the girl is allowed to complete her coursework - and the centre sometimes even gets additional patronage. In other cases, however, organization staff are unsuccessful and the family removes the girl from the centre.

\section{Observations}

An evaluation of AHIP services was recently conducted. A consultant assisted AHIP staff in collecting qualitative data from graduates. The results demonstrate clear benefits of the programme: 70 percent of the graduates interviewed reported using the skills they acquired. Many reported successfully earning incomes for themselves as well as dramatic changes in their ability to influence decisionmaking in the home. Unmarried and divorced adolescents reported that their opinion is now consulted when parents are making decisions relating to the family. Married adolescent girls indicated that their husbands now ask for their opinion when making decisions related to the household and to family health care seeking. Some girls said they had even begun to influence their husbands' financial decisionmaking. One young woman, for example, convinced her husband to purchase a new grinding machine. The machine would be used to make food for the family, she argued, as well as to produce food that they could sell for additional income. Married girls also reported feeling far more confident about running a household and about maintaining the physical health of their family.

Another result reported in the evaluations is that many centre graduates are imparting their learned skills and knowledge to others. Because graduation from the centre lends graduates a certain credibility and respect within the family and community, they are in a position to spread their knowledge and skills.

The training centre plans to expand to include counselling services for participants. These services will provide further education on young people's rights, build self-esteem, and help adolescents contribute to family decisionmaking. AHIP is working with the Population Council to determine how best to deliver these counselling services. Married adolescents will be among the target populations, and particular attention will be given to first-time mothers.

\section{FINAL THOUGHTS}

Evaluations were not available for most of the programmes included in Table 1. We did, however, glean some observations from the exercise of compiling the inventory. For one, it was encouraging to find programmes - even if relatively few and far between - from different parts of the world focusing on married adolescent needs. An interesting finding is that, as noted above, the programmes we looked at tended to be strong on providing information but weaker when it came to the provision of health services or efforts that aimed to address married girls' social and economic context. These are important gaps. Also of note is that some sub-groups appear to receive less attention than others. The husbands of married girls, for example, are 
largely neglected, despite their influential position within the household. Married girls in their first pregnancy also do not figure prominently in most of the projects, despite the potential opportunities presented by their impending transition to motherhood.

Each of the three projects profiled in greater depth above is exploring context-appropriate ways to address the needs of married adolescent girls and to support them in achieving better reproductive and sexual health. They have each explicitly targeted married adolescents in their program design, and have made special efforts to recruit this population into their programmes. They have each also recognized the need to take into account the views and demands of married adolescent girls' families in conceptualizing the timing and the venue of program activities, as well as the way program activities are framed and carried out. These projects demonstrated, however, that these requirements are not insurmountable obstacles; rather, it is possible to reach these vulnerable young women with careful efforts to involve gatekeepers and members of the community. As the evaluations of these efforts are completed, it will be instructive to see what lessons emerge, and how they will contribute to the body of knowledge that future projects for married adolescents can build on. 


\section{REFERENCES}

Amin, Sajeda, Simeem Mahmud, and Lopita Huq. 2002. "Baseline survey report on rural adolescents in Bangladesh.” Dhaka: Ministry of Women's Affairs, Government of Bangladesh.

Arens, Tom, Denise Caudill, Saraswati Gautam, Nicole Haberland, and Gopal Nakarmi. 2002. "If many push together, it can be done: Reproductive health and women's savings and credit in Nepal," in Responding to Cairo: Case Studies of Changing Practice in Reproductive Health and Family Planning, Nicole Haberland and Diana Measham (eds.). New York: Population Council.

Barker, Gary, Jorge Lyra, and Benedito Medrado. 2003. "The roles, responsibilities and realities of married adolescent males and adolescent fathers: A brief literature review," background paper prepared for the WHO/UNFPA/ Population Council technical consultation on married adolescents, Geneva, 9-12 December.

Barua, Alka and Kathleen Kurz. 2001. "Reproductive health-seeking by married adolescent girls in Maharasthra, India," Reproductive Health Matters 9(17): 53-62.

Brady, Martha. 2003. "Differentiating risk perception and protection needs across the marital transition," draft background paper prepared for the WHO/UNFPA/Population Council technical consultation on married adolescents, Geneva, 9-12 December.

Bruce, Judith and Shelly Clarke. 2003. "Including married adolescents in adolescent reproductive health and HIV/AIDS policy," background paper prepared for the WHO/UNFPA/ Population Council technical consultation on married adolescents, Geneva, 9-12 December.

Corona, Esther et al. 1988. "A study to evaluate the quality of care in a comprehensive model of service delivery to adolescent mothers in a Mexico City Hospital." Unpublished final technical report. Mexico City: Asociación Mexicana de Educación Sexual, A.C.

Haberland, Nicole. 2003. "The neglected majority: Married adolescents," in Adolescent and Youth Sexual and Reproductive Health: Charting Directions for a Second Generation of Programming, background document for a workshop of the UNFPA in collaboration with the Population Council. New York: Population Council.

Haberland, Nicole, Erica Chong, and Hillary Bracken. 2003. "Married adolescents: An overview," background paper prepared for the WHO/UNFPA/ Population Council technical consultation on married adolescents, Geneva, 9-12 December.

McNeil, P., A. Shillingford, M. Rattray, J.N. Gribble, P. Russell-Brown, and J.W. Townsend. 1988-89. The Effect of Continuing Education on Teenage Childbearing: The Jamaica Women's Center. Final Report. New York: Population Council; as cited in Barbara Barnett, Elizabeth Eggleston, Jean Jackson, and Karen Hardee. 1996. "Case study of the Women's Center of Jamaica Foundation Program for Adolescent Mothers." Research Triangle Park, NC: Family Health International. 
McNeil, Pamela. 1997. Women's Centre, Jamaica. Prevent Second Adolescent Pregnancies by Supporting Young Mothers. Washington, DC: Pathfinder International, FOCUS on Young Adults.

Miller, Suellen and Felicia Lester. 2003. "Meeting the needs of the youngest first time mothers," draft background paper prepared for the WHO/UNFPA/ Population Council technical consultation on married adolescents, Geneva, 9-12 December.

Pulerwitz, Julie, Gary Barker \& Márcio Segundo. (2004). Promoting healthy relationships and HIV/STI prevention for young men: Positive findings from an intervention study in Brazil, Horizons Research Update. Washington, DC: Population Council.

Rogow, Debbie, 2000. "Alone you are nobody, together we float: The Manuela Ramos Movement," Quality/Calidad/Qualité, Issue \#10.

Santhya, K.G. and Nicole Haberland. 2003. "Addressing the social context of married adolescent girls: The First-Time Parents Project," presentation at the WHO/UNFPA/Population Council technical consultation on married adolescents, Geneva, 9-12 December.

Santhya, K.G., F. Ram, Nicole Haberland, S.K. Mohanty, Elizabeth McGrory, R.K. Sinha, Arup Das, and Anupa Mehta. 2003. "The gendered experience of married adolescent girls in India: Baseline findings from the First-Time Parents Project," paper presented at the Second Asia and Pacific Conference on Reproductive and Sexual Health, Bangkok, 6-10 October.

Schuler, Sidney and Syed Hashemi, 1994. "Credit programs, women's empowerment, and contraceptive use in rural Bangladesh," Studies in Family Planning 25(2): 65-76.

Schuler, Sidney, Syed Hashemi, Ann Riley, and Shireen Akhter, 1996. "Credit programs, patriarchy and men's violence against women in rural Bangladesh," Social Science and Medicine 43(12):1729-1742.

Thapa, Shyam and Vinod Mishra. 2003. "Mass media exposure among youth in urban Nepal," Asia-Pacific Population Journal 18(1): 5-28.

Widge, Anjali, 2003. "Baseline Survey Results: Building Livelihoods Skills and Opportunities for Adolescent Girls in Ahmedabad and Vadodara Districts, Gujarat India," project update, unpublished. 


\section{APPENDIX}

Listed below are the 12 projects represented in the inventory of married adolescent programmes and the lead institutions involved.

AHIP: Adolescent Health and Information Projects; Nigeria; "Vocational Training Project." ALVF: Association to Eradicate Violence Against Women; Cameroon; "Maroua ALVF Center." APWA: All Pakistan Women's Association; Karachi, Pakistan; "Adolescent Reproductive Health Project."

FTP: Child in Need Institute, Deepak Charitable Trust and Population Council; Gujarat and West Bengal, India; "First-Time Parents Project."

HEAL: Heal Trust; Lahore, Pakistan; "Producing IEC Materials for Health Awareness."

ICRW/EH: International Center for Research on Women (ICRW) and EngenderHealth; Nepal;

"Adolescent Reproductive Health in Nepal: Using Participatory Methods to Define and Respond to Health Needs."

ICRW/FRHS: Foundation for Research in Health Systems and ICRW; Ahmedabad, India; "Community-Based Approach to Married Adolescent Girls' Reproductive Health."

PAPAI: Papai Institute; Brazil; "Adolescent Fatherhood: Action, Citizen, and Reproductive Rights."

PCBF: Population Council; Burkina Faso; "Strengthening Social and Health Services to Meet Adolescent Girls' Health and Development Needs in Burkina Faso."

PF: Pathfinder; Bangladesh; "Reaching Newlywed and Married Adolescents."

RUWSEC: Rural Women's Social Education Center; Tamil Nadu, India; "Work with Adolescents."

UNFPA: UNFPA; Bangladesh; "Bangladesh Married Adolescent Project." 